\title{
Building the evidence base for effective tobacco control policies: the International Tobacco Control Policy Evaluation Project (the ITC Project)
}

\section{G T Fong, K M Cummings, D R Shopland for the ITC Collaboration}

Tobacco Control 2006;15(Suppl III):iii1-iii2. doi: 10.1136/tc.2006.017244

\begin{abstract}
The Framework Convention on Tobacco Control (FCTC) is a seminal event in tobacco control and in global health. Scientific evidence guided the creation of the FCTC, and as the treaty moves into its implementation phase, scientific evidence can be used to guide the formulation of evidencebased tobacco control policies. The International Tobacco Control Policy Evaluation Project (ITC Project) is a transdisciplinary international collaboration of tobacco control researchers who have created research studies to evaluate and understand the psychosocial and behavioural impact of FCTC policies as they are implemented in participating ITC countries, which together are inhabited by over $45 \%$ of the world's smokers. This introduction to the ITC Project supplement of Tobacco Control presents a brief outline of the ITC Project, including a summary of key findings to date. The overall conceptual model and methodology of the ITC Project-involving representative national cohort surveys created from a common conceptual model, with common methods and measures across countries-may hold promise as a useful paradigm in efforts to evaluate and understand the impact of population-based interventions in other important domains of health, such as obesity.
\end{abstract}

\footnotetext{
$\mathrm{T}$
} obacco use, particularly the practice of cigarette smoking, is the second leading cause of premature death in the world. ${ }^{1}$ In recognition of the threat that tobacco use poses to global public health, in May 2003, the member countries of the World Health Organization adopted the Framework Convention on Tobacco Control (FCTC), the first international treaty devoted to health. ${ }^{2}$ To date, the FCTC has been ratified by over 120 countries.

Scientific evidence plays a central role in the FCTC. Its Foreword describes the FCTC as "an evidence-based treaty that reaffirms the right of all people to the highest standard of health". Its Preamble states that adopting nations are "determined to promote measures of tobacco control based on current and relevant scientific, technical, and economic considerations". And scientific evidence played a foundational role in the selection and form of the policies that are included in the FCTC.

The FCTC is a seminal event in global health. But the extent to which the FCTC will fulfill its objective of reducing the devastation of the tobacco epidemic will depend on whether the actual policies that parties will formulate and implement are effective. It stands to reason that research could and should also inform this critical implementation phase of the FCTC.

The International Tobacco Control (ITC) Policy Evaluation Project is a multi-country research initiative that was established to build the evidence base for the FCTC and to inform the creation of effective, evidence-based policies under the FCTC. The ITC Project is conducting research to measure the psychosocial and behavioural impact of FCTC policies, primarily those that aim to reduce demand.

The 12 original research articles contained in this Tobacco Control supplement introduce readers to the ITC Project. The lead article by Fong et $a l^{3}$ presents the conceptual model of the ITC Project. The ITC evaluation framework, which is described by Thompson et al, ${ }^{4}$ utilises multiple country controls, a longitudinal design, and a pre-specified, theorydriven conceptual model to test hypotheses about the anticipated effects of given policies. Nine of the 10 empirical articles included in this supplement summarise findings from the ITC Four Country Survey, which was initiated in 2002 and includes data on the smoking practices of random samples of over 2000 adult cigarette smokers in each of four countries-Australia, Canada, the United Kingdom, and the United States. The 10th empirical article reports findings from the ITC Ireland/UK Survey, which was designed to evaluate the 2004 comprehensive smoke-free law in the Republic of Ireland.

The ITC Project has grown so that it now consists of cohort surveys of representative samples of adult smokers in 12 countries-Canada, United States, United Kingdom, Australia, Ireland, Scotland, Thailand, Malaysia, South Korea, China, Mexico, and Uruguay, with additional countries and regions of the globe being added in the near future. All ITC surveys are guided by the same conceptual framework, with survey items that are standardised and consistent across countries. The evaluation research design and methods are identical or similar across countries and are as rigorous as the prevailing conditions allow in each country. Table 1 presents a summary of key findings from the ITC Project to date on tobacco use behaviours and the psychosocial precursors of such behaviours.

A central component of the ITC Project is the first-ever international repository of cigarettes, which is located at the Roswell Park Cancer Institute. The ITC Project Team, in collaboration with the US Centers for Disease Control and Prevention, are conducting studies to examine design features, smoke chemistries, and smoking behaviour (for example, puff topography) in an international context. In the same way as the ITC Surveys are designed to build the evidence base for the demand-reduction policies of the FCTC, research being conducted as part of the international product component of the ITC Project is designed to build the evidence base for tobacco product regulation, which is the focus of Articles 9 and 10 of the FCTC.

The use of parallel national cohort surveys of representative samples of populations across countries that vary along different dimensions (for example, geographic, economic development) yields a research programme of potentially great power not only for measuring the impact of tobacco control policies but also for addressing broader questions 
Table 1 Summary of findings from the ITC Four Country Survey

\begin{tabular}{ll}
\hline Policy (reference) & Findings \\
\hline Warning labels & Increasing warning label size makes the warning \\
& more salient and noticeable for smokers; increases \\
& content specific knowledge; and increases the \\
likelihood that smokers think about quiting smoking & and quit smoking. Graphic warning labels appear to \\
& have a greater impact than text only labels.
\end{tabular}

about patterns of tobacco use and cessation over time and across countries.

The concept and methods of the ITC Project constitute a research paradigm that could be applied not only to global tobacco control but also to evaluating and understanding policy-based approaches to other important health domains in which public health policies are being implemented or considered, such as in the domain of obesity.

\section{ACKNOWLEDGEMENTS}

The first two authors, on behalf of the ITC Collaboration, wish to express our gratitude to the third author, Donald R. Shopland, for his role as editor of this supplement of Tobacco Control.

\section{Authors' affiliations}

G T Fong, University of Waterloo, for the ITC Collaboration K M Cummings, Roswell Park Cancer Institute, for the ITC Collaboration D R Shopland, US Public Health Service (retired)

Funding sources: The ITC Project is supported by grants R01 CA 100362 and P50 CA111236 (Roswell Park Transdisciplinary Tobacco Use
Research Center) from the National Cancer Institute of the United States, Robert Wood Johnson Foundation (045734), Canadian Institutes of Health Research (57897), National Health and Medical Research Council of Australia (265903), Cancer Research UK (C312/A3726), Canadian Tobacco Control Research Initiative (014578), and the Centre for Behavioural Research and Program Evaluation, National Cancer Institute of Canada/Canadian Cancer Society. The funding sources had no role in the writing of this paper, and in the decision to submit this paper for publication.

Correspondence to: Geoffrey T Fong, PhD, Department of Psychology, University of Waterloo, 200 University Avenue West, Waterloo, Ontario N2L 3G1, Canada; gfong@uwaterloo.ca; or K Michael Cummings, PhD, $\mathrm{MPH}$, Department of Health Behavior, Division of Cancer Prevention and Population Sciences, Roswell Park Cancer Institute, Elm and Carlton

Streets, Buffalo, New York 14263; Michael.Cummings@Roswellpark.org

\section{REFERENCES}

1 Murray CJ, Lopez AD. Alternative projections of mortality and disability by cause 1990-2020: Global Burden of Disease Study. Lance 1997;349:1498-504.

2 World Health Organization. Tobacco Free Initiative. Information on global tobacco use. http://www.who.int/tobacco/health_priority/en/index.html.

3 Fong GT, Cummings KM, Borland R, et al. The conceptual framework of the International Tobacco Control (ITC) Policy Evaluation Project. Tob Control 2006;15(suppl III):iii3-11.

4 Thompson ME, Fong GT, Hammond D, et al. Methods of the International Tobacco Control (ITC) Four Country Survey. Tob Control 2006;15(suppl III):iii12-18.

5 Hammond D, Fong GT, McNeill A, et al. Effectiveness of cigarette warning labels in informing smokers about the risks of smoking: findings from the International Tobacco Control (ITC) Four Country Survey. Tob Control 2006;15(suppl III):iii19-25.

6 Borland R, Yong $\mathrm{H}-\mathrm{H}$, Siahpush M, et al. Support for and reported compliance with smoke-free restaurants and bars by smokers in four countries: findings from the International Tobacco Control (ITC) Four Country Survey. Tob Control 2006;15(suppl III):iii34-41.

7 Borland $\mathrm{R}$, Yong $\mathrm{H}-\mathrm{H}$, Cummings KM, et al. Determinants and consequences of smoke-free homes: findings from the International Tobacco Control (ITC) Four Country Survey. Tob Control 2006;15(suppl III):iii42-50.

8 Fong GT, Hyland A, Borland R, et al. Reductions in tobacco smoke pollution and increases in support for smoke-free public places following the implementation of comprehensive smoke-free workplace legislation in the Republic of Ireland: findings from the ITC Ireland/UK Survey. Tob Control 2006;15(suppl III):iii51-58.

9 Harris F, MacKintosh AM, Anderson S, et al. Effects of the 2003 advertising/ promotion ban in the United Kingdom on awareness of tobacco marketing: findings from the International Tobacco Control (ITC) Four Country Survey. Tob Control 2006;15(suppl III):iii26-33.

10 Borland R, Yong HH, King B, et al. Use of and beliefs about 'light' cigarettes in four countries: findings from the International Tobacco Control Policy Evaluation Survey. Nicotine Tob Res 2004;6(suppl 3):S31 1-21.

11 Fong GT. Evaluating the effects of the September 2003 European Union policy banning "Light/Mild" cigarette brand descriptors: findings from the International Tobacco Control Policy Evaluation Survey. Health Canada, 2005.

12 Hammond D, Fong GT, Cummings KM, et al. Smoking topography, brand switching, and nicotine delivery: results from an in vivo study. Cancer Epidemiology, Biomarkers and Prevention 2005;14:1370-5.

13 O'Connor RJ, McNeil A, Cummings KM, et al. How did UK cigarette makers get their brands to $10 \mathrm{mg}$. "tar" or less? BMJ 2006;332:302

14 O'Connor RJ, Giovino G, Fix B, et al. Smoker reactions to reduced ignition propensity cigarettes. Tob Control 2006;15:45-49.

15 Polzin GM, Vaughan CL, Tavakoli AD, et al. Analysis of physical characteristics and smoke chemistry of before and after changes in regulation. TTURC Symposium: Transdisciplinary Tobacco Use Research from Laboratory to the Population, Bethesda, Maryland:National Institutes of Health, 2005.

16 Hyland A, Laux FL, Higbee C, et al. Cigarette purchase patterns in four countries and the relationship with cessation: findings from the International Tobacco Control (ITC) Four Country Survey. Tob Control 2006; 15(suppl III):iii59-64.

17 Young D, Borland R, Hammond D, et al. Prevalence and attributes of rollyour-own smokers in the International Tobacco Control (ITC) Four Country Survey. Tob Control 2006;15(suppl III):iii76-82.

18 Siahpush M, McNeill A, Hammond D, et al. Socioeconomic and country variations in knowledge of health risks of tobacco smoking and toxic constituents of smoke: results from the 2002 International Tobacco Control (ITC) Four Country Survey. Tob Control 2006;15(suppl III):iii65-70.

19 Siahpush M, McNeill A, Borland R, et al. Socioeconomic variations in nicotine dependence, self-efficacy, and intention to quit across four countries: findings from the International Tobacco Control (ITC) Four Country Survey. Tob Control 2006;15(suppl III):iii71-75.

20 Hyland A, Borland R, Li Q, et al. Individual-level predictors of cessation behaviours among participants in the International Tobacco Control (ITC) Four Country Survey. Tob Control 2006;15(suppl III):iii83-94. 